RESEARCH ARTICLE

\title{
An Analytical Study on Relationship of Profile Characteristics with Effectiveness of Tribal FIGs in Tamil Nadu
}

\author{
Mathuabirami $\mathbf{V}^{*}$ and Kalaivani $\mathbf{S}$ \\ *Department of Agricultural Extension and Rural sociology, Tamil Nadu Agricultural University, Coimbatore-641 003
}

Received : $24^{\text {th }}$ May, 2020

Revised : 09 ${ }^{\text {th }}$ June, 2020

Accepted : $13^{\text {th }}$ June, 2020

\begin{abstract}
Indian Farmers Interest Group (FIG) is a self-managed, independent group of farmers with a shared goal and interest. FIG is usually formed by 15-20 members. When the farmers are facilitated to organize groups, trained and guided properly, they can attain tremendous development goal which would eventually make the group self-reliant and self-sufficient. Analyzing effectiveness of existing tribal FIGs will help to formulate a strategy for improving livelihood of the tribal farmer through collective action. This study was conducted in the Erode district of Tamil Nadu with a sample size of 100. The specific objective of this study is to study the relationship of profile characteristics with the effectiveness of tribal FIGs. The significant findings of the study revealed that tribal FIGs had medium level of effectiveness of tribal FIGs. Farming experience, information-seeking behavior, group cohesiveness and group communication of the respondents were the very significant variables contributing to the variation in the effectiveness of tribal FIGs.
\end{abstract}

Keywords: Tribes; Farmers Interest Groups (FIGs); Effectiveness; Correlation; Multiple Regression Analysis.

\section{INTRODUCTION}

The Government of India has promoted different forms of collectives namely Farmer Producer Organizations (FPOs), Farmers Interest Groups (FIGs) to deal with the challenges faced by the small and marginal farmers (Department of Agriculture \& Cooperation, 2013). Self Help Groups (SHGs), FIGs, Co-operatives Producers Associations, marketing associations etc. had bestowed in maximizing the input-output ratio and finally increasing the profit of producers (Nain et al. 2015). Farmers confidence level was enhanced through the establishment of FIGs (Singh and Srinivasan, 1998). Around the globe it is evidenced that the profitability in farming would be possible in groups rather than practicing it individually. Patil et al. (2014) had studied the impact of collective action of farmers through FIG (Farmer Interest Group) and reported that the cost of cultivation was reduced through sharing inputs and also it will lead to gain additional profit. This is particularly the case where farmers organize themselves as a response to credit and input needs, marketing concerns, etc., as there are clear economic benefits of working in groups. In areas where farmers are scattered geographically and communication is difficult, such organization plays a vital role. Such organization creates an opportunity for the participation of farmers and enables them to identify their own problems and found best solution for their issues through group action. Thus, it would also lead to build group cohesion and solidarity that encourage mutual support. Many governmental and Non-Governmental Organizations (NGO) had tried to organize farmers into groups and put together them into the advancement process by actively involving them in production, transfer of technology, planning, marketing, implementing and monitoring of different developmental projects on agriculture and rural development.

Tribes were blessed with ample of opportunities like forest resources for improving their livelihood. But geographical isolation restricts tribes to make use of their opportunities. They were facing problems in getting quality inputs and a good price for their produce. FIG is an innovative approach with an idea to develop a value chain for the produces, establish brand value and link the farmers with market and consumers. It was promoted with the purpose of collectivizing production especially at small holder level and empower them for better bargaining power. Tribal FIGs will play a unique role in improving economic status of tribal people through which they can access credit, market facilities and value-added forest produce. FIG consists of 15 to 20 members. Thus, the effective functioning of tribal FIGs is essential. Therefore, analyzing the effectiveness of existing tribal FIGs results in formulating a strategy to improve the livelihood of 
the tribal farmer through collective action. Hence the study has been attempted with a specific objective to study the relationship of profile characteristics with the effectiveness of tribal FIGs.

\section{MATERIAL AND METHODS}

The research design adopted for this study is ex-post-facto design. Erode district was purposively selected for conducting the study. Thus MYRADA KVK, Erode had been assigned as a resource agency for the promotion of one FPO in Erode district of Tamil Nadu supported under Tamil Nadu Small Farmers Agribusiness Consortium (TNSFAC) to increase the income level of the farmers by building, knowledge and facilitating supply inputs and linking to markets for produces. MYRADA KVK had planned to establish FPO through promoting Farmer Interest Groups (FIGs) concept among tribes. Dimbam Dhaniya Farmer Producer Company Limited (DDFPCL) comprises of 62 FIGs covering 27 villages. FIGs were federated into DDFPCL. Out of these 27 villages, nine villages were dominated by tribes, namely Chilumaiedoddi, Devarnatham, Pudhukadu, Guliyada, Sujjalakare, Kottamalam, Bejjalatti, Galidimbam and Ittarai. A total of four Tribal FIGs were randomly selected from 16 Tribal FIGs belonging to DDFPCL, and by employing the whole sampling method, all the members of four selected FIGs were considered constituting to a sample size of 100 .

A well-structured interview schedule was prepared to collect the data. Correlation and multiple regression analyses were used for analyzing the data to study the relationship of selected independent variables with the dependent variable, the effectiveness of tribal FIGs. The details of selected Tribal FIGs are furnished in Table 1.

\section{RESULTS AND DISCUSSION}

\section{Overall Effectiveness of tribal FIGs}

The functioning of tribal FIGs was assessed through the effectiveness factor. The effectiveness of tribal FIGs was studied through five subcomponents. The overall group effectiveness was carefully investigated through five sub-components namely organizational management, organizational accountability, financial management, linkages with organization and monitoring and evaluation of Farmer Interest Groups. The individual score for each sub-component was cumulated to calculate the overall effectiveness of tribal FIGs. The distribution of respondents according to the overall Effectiveness of Tribal FIGs is presented in Table 2.

Table 1. Details of selected Tribal FIGs

\begin{tabular}{lcc}
\hline Name of the village & Name of FIG & No. of members \\
\hline Guliyada & Kadehatti Muniyappan FIG & 15 \\
& Periyasamyaiyyan FIG & 16 \\
Sujjalakare & Sri Karppusamy FIG & 25 \\
Kottamalam & Sri Magaliamman FIG & 24 \\
Ittari & Ilandhalir FIG & 20 \\
& Total & 100 \\
\hline
\end{tabular}

It is clear from Table 2 that $83.00 \%$ of the members admitted that tribal FIGs had medium to high levels of overall effectiveness and the rest of them reported that tribal FIGs had low level of overall effectiveness and was due to the backhand support of MYRADA KVK. MYRADA KVK had appointed CEO, computer operator, accountant, field-level staff to collect and maintain the data of the members of tribal FIGs, monitoring functioning of tribal FIGs, carry out business operation, monitor financial activities, organize training and linking with external organizations.

Table 2. Effectiveness of tribal FIGs $(n=100)$

\begin{tabular}{lrr}
\hline Category & No. & \% \\
\hline Low & 17 & 17.00 \\
Medium & 55 & 55.00 \\
High & 28 & 28.00 \\
Total & 100 & 100.00 \\
\hline
\end{tabular}

These results are in line with the findings of Sreevalsan et al. (2012) and Haryadi et al. (2014) and contradictory with the findings of Borah et al. 2016.

\section{Relationship of profile characteristics with effectiveness of tribal FIGs}

In social science, it is essential to analyze the characteristics of farmers, which would give a basic and clear understanding of the background of the farmers. This would help in interpreting the data gathered effectively. Profile characteristics of the members of tribal FIGs studied through sixteen variables such as age, gender, educational status, annual income, farm size, farming experience, institutional support, training undergone, economic motivation, information-seeking behavior, group communication, group leadership, group cohesiveness, decision-making pattern, selfconfidence and self-reliance. In order to find out the relationship between profile characteristics of the respondents and their effectiveness of Tribal FIGs, correlation and multiple regression analyses were worked out and the details are given in Table 3. 
Correlation analysis was carried to study the relationship of profile characteristics with the effectiveness of tribal FIGs. It could be seen from Table 3 that out of 16 independent variables three variables namely Information seeking behavior $\left(X_{10}\right)$, Group communication $\left(X_{11}\right)$ and Group cohesiveness $\left(X_{13}\right)$ had shown a positive and significant relationship with the effectiveness of tribal FIGs at $1 \%$ level of probability. In contrast, Annual income $\left(X_{4}\right)$ had a positive and significant relationship with the dependent variable, effectiveness of tribal FIGs at $5 \%$ level of probability. Economic motivation $\left(X_{9}\right)$ and Decision-making pattern $\left(X_{14}\right)$ were found to have significant and negative relationship with the dependent variable at one per cent probability level. These findings were in conformity with results of Karthick (2014) and Naveen Kumar and Rathakrishnan (2017). It could be justified that group related variables viz., group communication and group cohesiveness is very much essential for effectiveness of tribal FIGs and also informationseeking behavior is essential because this would help to increase social contact and make them to understand the effective functioning of FIGs.

$$
\begin{aligned}
& \mathrm{R}^{2}=0.560 * *=\text { significant at } 1 \% \text { level } \\
& \mathrm{F}=6.6 * \text { significant at } 5 \% \text { level } \\
& \mathrm{NS}=\text { Non significant } r-\text { Correlation coefficient }
\end{aligned}
$$

It could also be seen that from Table 3 that other variables Age $\left(X_{1}\right)$, Gender $\left(X_{2}\right)$, Educational status $\left(X_{3}\right)$, Farm size $\left(X_{5}\right)$, Farming experience $\left(X_{6}\right)$, Institutional support $\left(X_{7}\right)$, Training undergone $\left(X_{8}\right)$, Group leadership $\left(X_{12}\right)$, Self Confidence $\left(X_{15}\right)$ and Self-reliance $\left(X_{16}\right)$ had shown a non-significant relationship with effectiveness of tribal FIGs.

Table 3. Simple Correlation coefficient and Multiple regression analysis of independent variables towards the Effectiveness of tribal FIGs $n=100$

\begin{tabular}{lccc}
\hline Variables & 'r' values & Regression Co efficient & 't' values \\
\hline Age $\left(X_{1}\right)$ & $-0.121^{\mathrm{NS}}$ & -2.294 & $-1.996^{\mathrm{NS}}$ \\
Gender $\left(\mathrm{X}_{2}\right)$ & $0.164^{\mathrm{NS}}$ & 1.190 & $0.944^{\mathrm{NS}}$ \\
Educational status $\left(\mathrm{X}_{3}\right)$ & $-0.010^{\mathrm{NS}}$ & -0.494 & $-1.217^{\mathrm{NS}}$ \\
Annual Income $\left(\mathrm{X}_{4}\right)$ & $0.242^{*}$ & 0.669 & $0.625^{\mathrm{NS}}$ \\
Farm Size $\left(\mathrm{X}_{5}\right)$ & $-0.062^{\mathrm{NS}}$ & -1.690 & $-1.433^{\mathrm{NS}}$ \\
Farming experience $\left(\mathrm{X}_{6}\right)$ & $0.072^{\mathrm{NS}}$ & 2.590 & $2.00^{*}$ \\
Institutional support $\left(\mathrm{X}_{7}\right)$ & $0.012^{\mathrm{NS}}$ & -0.768 & $-0.452^{\mathrm{NS}}$ \\
Training undergone $\left(\mathrm{X}_{8}\right)$ & $0.119^{\mathrm{NS}}$ & -0.620 & $-0.855^{\mathrm{NS}}$ \\
Economic motivation $\left(\mathrm{X}_{9}\right)$ & $-0.551^{* *}$ & -2.380 & $-1.171^{\mathrm{NS}}$ \\
Information seeking behavior $\left(\mathrm{X}_{10}\right)$ & $0.514^{* *}$ & 3.269 & $2.267^{*}$ \\
Group communication $\left(\mathrm{X}_{11}\right)$ & $0.582^{* *}$ & 4.351 & $2.602^{*}$ \\
Group leadership $\left(\mathrm{X}_{12}\right)$ & $0.010^{\mathrm{NS}}$ & 2.484 & $1.519^{\mathrm{NS}}$ \\
Group cohesiveness $\left(\mathrm{X}_{13}\right)$ & $0.520^{* *}$ & 3.441 & $2.459^{* *}$ \\
Decision making pattern $\left(\mathrm{X}_{14}\right)$ & $-0.277^{* *}$ & -4.536 & $-2.438^{* *}$ \\
Self confidence $\left(\mathrm{X}_{15}\right)$ & $0.28^{\mathrm{NS}}$ & 0.544 & $0.454^{\mathrm{NS}}$ \\
Self reliance $\left(\mathrm{X}_{16}\right)$ & $0.050^{\mathrm{NS}}$ & -0.535 & $-0.591^{*}$ \\
\hline
\end{tabular}

Multiple regression analysis was carried out to study the strength of the relationship between the independent variables and the dependent variable. It could be seen from Table 3 that the $\mathrm{R}^{2}$ value was 0.560 , which revealed that the sixteen independent variables taken together explained for $56 \%$ per cent of variation in the dependent variable viz., Effectiveness of tribal FIGs. The 'F' value of 6.6 was significant at $1 \%$ level of probability. Since the ' $F$ ' value was significant the prediction equation was fitted for the effectiveness of tribal FIGs and the same is given here under.
$Y=56.316-2.294(X 1)+1.190(X 2)-0.494$ (X3)+0.669(X4)-1.690 (X5)

$$
+2.590(X 6)-0.768(X 7)-0.620(X 8)-2.380
$$$$
(X 9)+3.269(X 10)+4.351(X 11)
$$$$
+2.484(X 12)+3.441(X 13)-4.536(X 14)+
$$
0.544 (X15)-0.535 (X16)

From the results, it could be observed that the value of regression co-efficient for the variable group cohesiveness $\left(X_{13}\right)$ was found to have a positive and significant relationship with Effectiveness of tribal FIGs at one per cent level of probability and variables 
like farming experience $\left(X_{6}\right)$,information-seeking behavior $\left(X_{10}\right)$ and group communication $\left(X_{11}\right)$ were found to have a positive and significant relationship at five per cent level of probability. This suggested that a unit increase in group cohesiveness, farming experience, information seeking behavior and group communication would increase the Effectiveness of tribal FIGs by 3.441, 2.590, 3.269 and 4.351 units respectively. Hence, it may be concluded that farming experience, information-seeking behavior, group communication and group cohesiveness of the respondents were the very important variables contributing to the variation in the effectiveness of tribal FIGs.

Farming experience had a significant and positive relationship with effectiveness. Tribal farmers with high experience in farming had greater exposure. They underwent group activity patiently and their expertise had guided them to know what is right what is wrong, what to do for the welfare of FIGs. Therefore, farming experience is very much essential for effectiveness of tribal FIGs. Group cohesiveness is the bond that draws the members of FIGs to each other through resisting separation and hence increased group cohesiveness had increased the effectiveness of the group. Communication is essential everywhere which would help to share the minutes of meetings, experience and to maintain transparency regarding loan processing among the members of tribal FIGs and therefore group communication had contributed to effectiveness.

Here, the decision-making pattern was found to be negative and significant at one per cent level of probability. This finding is in line with the result of Naveen Kumar and Rathakrishnan (2017). This suggested that a unit increase in decision-making pattern would decrease the Effectiveness of tribal FIGs by 4.536 units. Self-reliance also had showed a negative and significant relationship to the Effectiveness of tribal FIGs at five per cent level of probability and hence one unit increase in Effectiveness of tribal FIGs would decrease the Effectiveness of tribal FIGs by 0.535 units.

\section{CONCLUSION}

Group related variables such as group cohesiveness, group communication and information-seeking behavior of the members of tribal FIGs were the contributors for the effectiveness of tribal FIGs. The findings of the study also revealed that members of tribal FIGs had medium to high levels of overall effectiveness. To improve the effectiveness of tribal FIGs measures should be taken to increase the level of group communication, group cohesiveness and information-seeking behavior. This can be increased through regular meetings for members, frequent visit of extension officials and make the members understand the importance of group action.

\section{REFERENCES}

Borah, D, RK Talukdar, S Barman, and R Boruah. (2016). 'Effectiveness of Farmers' Groups Organized under Agricultural Technology Management Agency (ATMA) in Jorhat, Assam." Indian Research Journal of Extension Education 15(1): 84-88.

Department of Agriculture \& Cooperation (2013) 'Policy and Process Guidelines for Farmer Producer Organizations', Ministry of Agriculture, Government of India.

Haryadi, F Trisakti, Budi Guntoro, Endang Sulastri, R Ahmad Romadhoni and Siti Andarwati. (2014). “The effectiveness of farmers' group functions in creating self-sustain of beef cattle farming activities."Proceedings of the $16^{\text {th }}$ AAAP Animal Science 2: 1045-1048.

Karthick, D. (2014). "A Study on the Effectiveness of Cotton Farmer Groups in Warrangal District of Andhra Pradesh." Acharya NG Ranga Agricultural University, Rajendranagar, Hyderabad.

Nain, MS, Rashmi Singh, Shiv Kumar, and VP CHAHAL. (2015). 'Farmers' producer organisation in reducing transactional costs: A study of Tamil Nadu Mango Growers Federation (TAMAFED)." Indian Journal of Agricultural Sciences 85(10): 1303-7.

Naveen Kumar, MR, and T. Rathakrishnan. (2017). "A Study on Relationship of Characteristics and Performance of Guava Farmer Interest Groups in Tamil Nadu." Madras Agricultural Journal 104.

Patil, Suresh S, GM Hiremath, and GB Lokesh. (2014). "Economic Sustainability through Farmers Interest Groups and their Linkage with Institutional Agencies-An Evidence from Karnataka." Agricultural Economics Research Review 27(347-201617143): 141-146.

Singh, Katar, and R Srinivasan. (1998). "Role of farmers' organization in the context of new economic policy with particular reference to agriculture marketing and agro-processing." Indian J. Agrl. Mktg : 161164.

Sreevalsan, J, Jojo Anto, and C Sowmya. (2012). "Effectiveness of farmer groups-the case of Pananchery farmers' club." International Journal of Recent Scientific Research. 3: 8690. 